\title{
Primary chest wall abscess caused by tuberculous costal chondritis: A case report
}

\author{
Omar Toumi ${ }^{1 *}$, Houssem Ammar ${ }^{1}$, Sadok Ben Jabra ${ }^{1}$, Mariem Ayed ${ }^{1}$, Hanen Znaiti ${ }^{1}$, Faouzi Noomene ${ }^{1}$, Khadija Zouari ${ }^{1}$, Randa Salem ${ }^{2}$, \\ Rahul Gupta ${ }^{3}$, Jamel Saad ${ }^{2}$ and Mondher Golli ${ }^{2}$ \\ ${ }^{1}$ Department of surgery, Fattoumabourguiba hospital, Monastir, Tunisia \\ ${ }^{2}$ Department of Radiology, Fattoumabourguiba hospital, Monastir ,Tunisia \\ ${ }^{3}$ Department of HPB surgery and Liver transplantation, CARE hospital, Hyderabad, India
}

\begin{abstract}
Introduction: Mycobacterium tuberculosis can affect almost any part of the body. Although tuberculosis of the bones is well known, tuberculosis involving the cartilages is rarely described.

Presentation of case: We report a 30 year male, who presented with insidious onset pain and swelling of the right lower parasternal area which on evaluation was diagnosed as tubercular infection of costochondral junction. The patient had no evidence of tuberculosis anywhere else in the body.

Discussion: Bone and joint tuberculosis is a rare location of extra-pulmonary tuberculosis. It predominates at the spine and large joints (hip, knee). The costal involvement is extremely rare location, and primary tubercular costo chondritis is an exceptional form and has been very rarely reported in the literature.

Conclusion: This case illustrates that primary rib cartilage tuberculosis is a rare disorder worldwide, and needs high index of suspicion for diagnosis, based on clinical, radiological and microscopical backgrounds.
\end{abstract}

\section{Introduction}

Tuberculosis continues to be a major international problem especially in less developed countries. The rib is an extremely rare site for osteo-articular tuberculosis, and involvement of costochondral junction is among the rarest forms of tuberculosis even in countries where tuberculosis is common [1,2]. Chest wall tuberculosis is still a diagnostic and therapeutic challenge. Tubercular costochondritis usually presents with insidious onset, vague indolent symptoms with non- specific pain and swelling, resulting in delay in the diagnosis. The diagnosis of rib cartilage tuberculosis is crucial in order to differentiate it from a benign or malignant bone tumor, or other kinds of bacterial infections [2]. A high index of suspicion for tuberculosis is essential in making an early diagnosis. The definitive diagnosis is suspected by typical radiological findings and confirmed by microbiological and histological evidence of tuberculosis. Treatment consists of antitubercular therapy with or without surgery.

We here in report an unusual case of chondrocostal tuberculosis presenting as a swelling over the left lower parasternal area $[3,4]$. The objective of the current paper is to evaluate the clinical, radiographic findings and the management of this extremely rare condition.

\section{Case report}

A 35-year-old Tunisian woman, with no history of tuberculosis presented with chest pain and swelling over the lower left anterior parasternal chest wall without respiratory symptoms. The patient reported history of progressive weight loss and low grade intermittent fever, malaise and anorexia which began gradually one year back. She was BCG vaccinated and there was no history of contact with tuberculosis in the family.
On examination, the temperature was $37.8^{\circ} \mathrm{C}$. The local examination showed swelling over the anterior aspect of left lower parasternal chest wall. The swelling was tender and fluctuant. There was no redness, localized rise of skin temperature or any venous prominence over the swelling. There was no palpable lymphadenopathy. Preoperative blood test revealed microcytic hypochromic anemia and white blood cell count, $\mathrm{C}$ - reactive protein and erythrocyte sedimentation rate were normal.

Chest radiography was normal. A CT- scan showed a Subcutaneous soft tissue thickening in the left parasternal region over the anterior arch of left $11^{\text {th }}$ rib costochondral area, extending and eroding posteriorly into the costal cartilage which was enlarged and containing a centimetric hypodense area. There was no associated parenchymal or pleural lesion (Figure 1). The most likely diagnosis was pyogenic costochondral infection. The surgical exploration found a cold abscess filled with caseous material eroding into the body of the left $11^{\text {th }}$ rib, which was curetted and partially excised. The histological examination showed a large area of caseous necrosis bordered by epitheloid cells, some of which contained calcified inclusions. Giant cells and focus of caseous necrosis were observed. Chronic inflammatory cells, mostly plasma cells and lymphocytes, were present throughout (Figure 2).

Correspondence to: Omar Toumi, Department of surgery, Fattoumabourguiba hospital, Monastir, Tunisia, Tel: +21652688551; E-mail: toumi.amor@rns.tn

Key words: tuberculosis, skeletal, rib, osteitis, case report

Received: March 17, 2017; Accepted: April 18, 2017; Published: April 20, 2017 


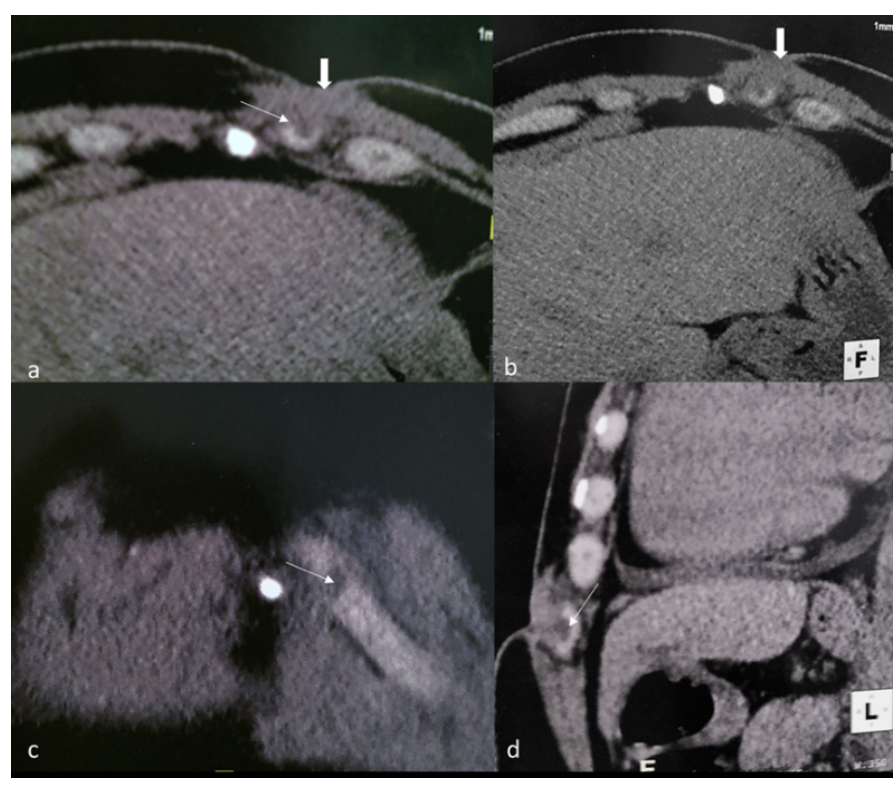

Figure 1. a and b axial, c coronal and d sagittal non enhanced CT scan images of the ches of a patient with costochondral tuberculosis showed a Subcutaneous soft tissue thickening in the left parasternal region over the anterior arch of left 6 th rib costochondral area, extending and eroding posteriorly into the costal cartilage which is containing a centimetric hypodense area.

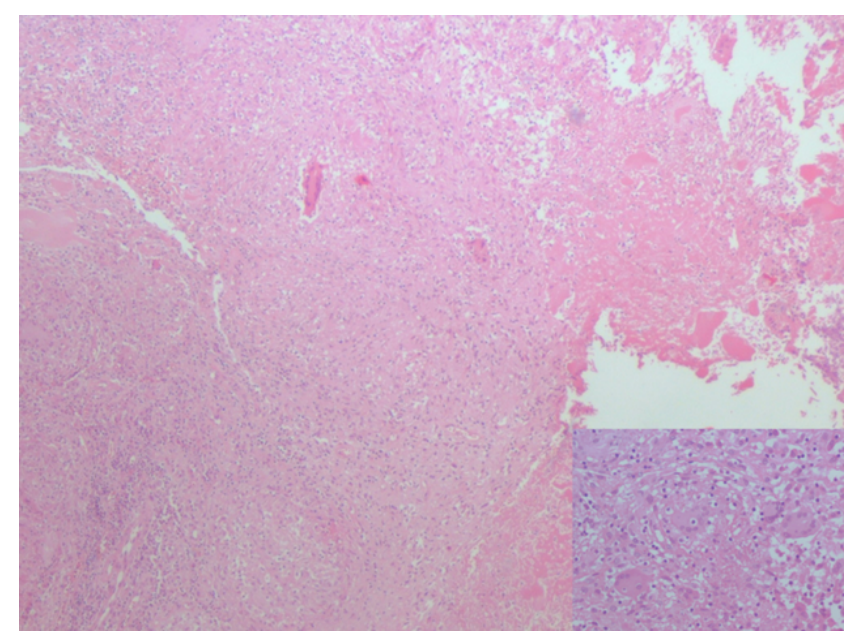

Figure 2. Histological examination showed large area of caseous necrosis bordered by epitheloid cells.

Ziehl-Neelson stain showed acid fast bacilli within the granuloma. The cultures were positive for Mycobacterium tuberculosis.

The diagnosis was consistent with costochondral cold abscess tuberculosis. CT- scan failed to demonstrate evidence of contiguous spread from nodes or lung parenchymal tuberculous lesion.

The patient was treated with Rifampicin, Isoniazid and Pyrazinamide for two months followed by Rifampicin and Isoniazid for another 7 months, and there was no evidence of relapse after one year of follow up.

\section{Discussion}

Skeletal tuberculosis accounts for 1-5\% of all tuberculous infections. The spine is the most commonly affected site with nearly $50 \%$ of cases [1]. The involvement of the ribs is extremely rare, with an incidence rate at $<5 \%$ of bone and joint tuberculosis $[5,6]$. In developing countries, tuberculosis is endemic and all the rare forms of the disease have been described, but in developed countries, atypical presentations may occur in cases of tuberculosis resurgence or could be seen in HIV patients.

Rib osteomyelitis caused by Tuberculosis is a rare disease and few cases have been reported to date. Tuberculosis of the rib occurs in males about twice as often as it does in females [4,7]. Thisrib infection occurs most often in patients between 15 and 30 years of age, in contradiction with the patients with bone tuberculosis, which occurs most often in children between the age of 2 and 10 years [8]. TB abscesses of the chest wall are usually seen at the margins of the sternum and along the rib shafts, and can also involve the costochondral junctions, costovertebral joints and the vertebrae.

Based on the part of the rib involved, rib tuberculosis are divided into osteochondritis involving the costochondral junction, with and without rib destruction, costal tuberculosis involving the shaft of the rib and costovertebral tuberculosis [8,9]. Our case is particular by the primitive unique location of tuberculosis in the costal cartilage.

It is commonly caused by spontaneous reactivation of latent foci formed during haematogenous or lymphatic dissemination that occurred in the primary stage [10]. Direct contagious spread can also occur. In a series in which the skeletal remains of the patients with chronic pulmonary tuberculosis were reviewed, periostitis of the rib adjacent to a pulmonary lesion was found in $8 \%$ of cases [11]. Our patient had primitive costochondral tuberculosis, he denied any contact or history of tuberculosis and CT scan did not show any evidence of mediastinal, lung parenchymal or pleural involvement.

The extra-pulmonary signs of tuberculosis may resemble other conditions such as bacterial and fungal infections, fibrous dysplasia, osteoblastoma, chondral tumors such as chondroma or malignant bony or cartilaginous tumors [1]. The clinical presentation used to be insidious with localized pain, swelling as predominant symptoms. This presentation contrasts with pyogenic rib osteomyelitis, in which the onset used to be rapid with more prominent systemic symptoms [12]. The etiology of a cold abscess often cannot be distinguished, as in our case.

Our patient presented with a painful swelling over the left anterior parasternal chest wall area as initial manifestation of costal cartilage tuberculosis. In this case, preoperative diagnosis was pyogenic infection due the clinical presentation.

The diagnosis of extra-pulmonary tuberculosis is difficult and often made postoperatively. Delay in diagnosis is common, averaging 4-28 months [13]. In our case the diagnosis delay was 1 year. A chest $\mathrm{X}$-Ray, may show osteopenia, soft tissue swelling and minimal periosteal reaction. In this case the chest X -Ray was normal. However, a normal chest X-Ray does not exclude the possibility of current or previous tuberculosis infection. Ultrasonography is a useful imaging technique to demonstrate the focus of bone infection and the extent of the disease [13]. The next diagnosis procedure would be chest CTscan with good sensitivity and specificity for osteomyelitis. This exam does not differentiate between infecting agents, and can be useful to rule out pulmonary or node involvement [10]. The typical findings of CT images on bone setting is features of centrally-low attenuation with peripheral rim enhancement of soft tissue lesion $[14,15]$ as shown in our case.

Magnetic Resonance Imaging appears to be slightly superior to CT in disclosing the characteristics, the extent of mass and the location [16]. Percutaneous needle aspiration and biopsy is the most likely 
procedure to have relatively non-invasive features [17]. In order to achieve positivity of sampling, an exact location from an imaging study is necessary. Smear and culture of acid fast bacilli from the aspirates should be obtained whenever tuberculosis is suspected. Recently, polymerized chain reaction was shown to be a sensitive method for the detection of tuberculosis bacilli from the aspirates [18]. Tuberculin positivity in adult population is so high in tuberculosis endemic countries that the tuberculin test was not helpful in diagnosis.

Many Complications of thoracic wall tuberculosis may occur including extension of tuberculosis abscess into the mediastinum, pleural cavity, lung parenchyma or subcutaneous tissues as discharging sinus. Secondary infection, spontaneous fractures of the sternum, compression or erosion of the large blood vessels was also reported. In our patient there was no complication and the infection was confined to costal cartilage and adjacent subcutaneous tissues.

There is still no consensus on the optimal therapy of chest wall tuberculosis. But current recommendations for the treatment of rib tuberculosis include a two-month initial phase of Isoniazid, Rifampicin, Ethambutol, Pyrazinamide followed by a six to twelve months regimen of Isoniazid and Rifampicin [1].

Surgical debridement ad curettage of affected bone in skeletal tuberculosis has been recommended because it removes bacilli sequestrated in necrotic tissue, which is inaccessible to early healing [1]. Our patient responded well to this adjuvant medical treatment.

\section{Conclusion}

This case illustrates that primary rib cartilage tuberculosis is a rare disorder worldwide, and needs high index of suspicion for diagnosis, based on clinical, radiological and microscopical backgrounds.

Physicians should always put costal tuberculosis in the list of differential diagnosis. Until now there has been no standard treatment. However, it's believed that the conservative management with antituberculous agent should be first line treatment, in case of failure of this treatment, surgical intervention can be considered.

\section{Financial support}

None.

\section{Conflict of interest}

The authors have no conflict of interest to declare.

\section{Patient consent}

Informed consent was taken from the patient for case publication.

\section{References}

1. Manish N, Archana D, Shiva N, Gopesh M (2011) Sternal Tuberculosis: An Uncommon Presentation. Case Report JCR 1: 9-11.

2. Chang JH, Kim SK, Lee WY (1999) Diagnostic issues in tuberculosis of the ribs with a review of 12 surgically proven cases. Respirology 4: 249-253. [Crossref]

3. Lakranbi M, Smahi M, Ouadnouni Y, Msougar Y, Caidi M, et al. (2010) Ostéite costale tuberculeuse. Pan African Medical $J$ 6: 1 .

4. Vasa M, Ohikhuare C, Brickner L (2009) Primary sternal tuberculosis osteomyelitis A case report and discussion. Can J Infect Dis Med Microbiol 20: e181. [Crossref]

5. Rasool MN (2001) Osseous manifestations of tuberculosis in children. $J$ Pediatr Orthop 21: 749-755. [Crossref]

6. Wiebe ER, Elwood RK (1991) Tuberculosis of the ribs--a report of three cases. Respir Med 85: 251-253. [Crossref]

7. Asnis DS, Niegowska A (1997) Tuberculosis of the rib. Clin Infect Dis 24: 1018-1019. [Crossref]

8. Tatelman M, Drouillard EJ (1953) Tuberculosis of the ribs. Am J Roentgenol Radium Ther Nucl Med 70: 923-935. [Crossref]

9. Lee SH, Abramson SB (1996) Infections of the musculoskeletal system by M.tuberculosis. In: Rom WN, Garay SM, eds. Tuberculosis. New York: Little Brown, Pp. 635-644.

10. Rivas P, Górgolas M, Gimena B, Sousa J, Fernández-Guerrero ML (2005) Sternal tuberculosis after open heart surgery. Scand J Infect Dis 37: 373-374. [Crossref]

11. Kelley MA, Micozzi MS (1984) Rib lesions in chronic pulmonary tuberculosis. Am J Phys Anthropol 65: 381-386. [Crossref]

12. McLellan DG, Philips KB, Corbett CE, Bronze MS (2000) Sternal osteomyelitis caused by mycobacterium tuberculosis: case report and review of the literature. Am J Med Sci 319: 250-254. [Crossref]

13. Laube S, Clarke J, Parikh DH, Moss C (2005) Tuberculous cold abscess resembling a lymphatic malformation. Clin Exp Dermatol 30: 611-613. [Crossref]

14. FitzGerald R, Hutchinson CE (1992) Tuberculosis of the ribs: computed tomographic findings. Br J Radiol 65: 822-824. [Crossref]

15. Lee G, Im JG, Kim JS, Kang HS, Han MC (1993) Tuberculosis of the ribs: CT appearance. J Comput Assist Tomogr 17: 363-366. [Crossref]

16. Sharif HS, Clark DC, Aabed MY, Aideyan OA, Haddad MC, et al. (1990) MR imaging of thoracic and abdominal wall infections: comparison with other imaging procedures. AJR Am J Roentgenol 154: 989-995. [Crossref]

17. Lemaître F, Damade R, Pouchot J, Barge J, Boussougant Y, et al. (1995) [Osteoarticular tuberculosis. Diagnostic contribution of local sampling]. Rev Med Interne 16: 191-194. [Crossref]

18. Godfrey-Faussett P, Wilkins EG, Khoo S, Stoker N (1991) Tuberculous pericarditis confirmed by DNA amplification. Lancet 337: 176-177. [Crossref]

Copyright: (C2017 Toumi O. This is an open-access article distributed under the terms of the Creative Commons Attribution License, which permits unrestricted use, distribution, and reproduction in any medium, provided the original author and source are credited. 